\title{
The cognitive processing of film and musical soundtracks
}

\author{
MARILYN G. BOLTZ \\ Haverford College, Haverford, Pennsylvania
}

\begin{abstract}
Previous research has demonstrated that musical soundtracks can influence the interpretation, emotional impact, and remembering of film information. The intent here was to examine how music is encoded into the cognitive system and subsequently represented relative to its accompanying visual action. In Experiment 1, participants viewed a set of music/film clips that were either congruent or incongruent in their emotional affects. Selective attending was also systematically manipulated by instructing viewers to attend to and remember the music, film, or both in tandem. The results from tune recognition, film recall, and paired discrimination tasks collectively revealed that mood-congruent pairs lead to a joint encoding of music/film information as well as an integrated memory code. Incongruent pairs, on the other hand, result in an independent encoding in which a given dimension, music or film, is only remembered well if it was selectively attended to at the time of encoding. Experiment 2 extended these findings by showing that tunes from mood-congruent pairs are better recognized when cued by their original scenes, while those from incongruent pairs are better remembered in the absence of scene information. These findings both support and extend the "Congruence Associationist Model" (A. J. Cohen, 2001), which addresses those cognitive mechanisms involved in the processing of music/film information.
\end{abstract}

Film theorists have long acknowledged the role of music within the movie-viewing experience (Bordwell \& Thompson, 1979; Giannetti, 1982; Johnson, 1969), and during the past decade, a number of psychological studies have found that music does in fact exert a significant impact upon the perception, interpretation, and remembering of film information. However, what remains unclear is whether music is encoded into the cognitive system during movie viewing, and if so, in what manner? Is music jointly encoded with its corresponding visual images, such that attending to one dimension leads to an incidental learning of the other? Alternatively, such a strategy may exceed a viewer's attentional capacity, such that encoding only occurs if a given dimension, music or film, is selectively attended to independently of the other. Finally, beyond the issue of encoding, how music is represented in memory relative to film is also a question that remains unanswered.

\section{The Influence of Music on the Perception and Interpretation of Filmed Events}

Filmmaking primarily relies on the visual medium to relate a story. Nonetheless, the accompanying soundtrack is an integral component that conveys not only the

This research was supported by a Faculty Research Grant from Haverford College. The author thanks Cathleen Mitchell, Michael Smyth, and Eula Jackson, who conducted a pilot study for Experiment 1 as part of their senior thesis requirement. In addition, Annabel Cohen and two anonymous reviewers are greatly appreciated for providing critical comments on an earlier version of this paper. All correspondence should be addressed to M. Boltz, Department of Psychology, Haverford College, Haverford, PA 19041 (e-mail: mboltz@haverford.edu). characters' dialogue but, of greater interest here, a musical score that can contribute to the story's meaning. One common technique is to play music in parallel with a given episode to enhance or diminish its emotional impact. Through the structural interplay of pitch, timing, and loudness characteristics, music can evoke different moods (Hevner, 1936; Levi, 1982; Rigg, 1964; Scherer, 1979) that are then incorporated into the ongoing visual action. For example, the eeriness of a mystery or the tenderness of a romance can be intensified with music of a similar affect. On other occasions, a technique known as ironic contrast (Bordwell \& Thompson, 1979; Giannetti, 1982) may be used to distill the extreme negativity of a scene. The movies Bonnie and Clyde and A Clockwork Orange provide examples of violent episodes that are accompanied by incongruent music.

Several empirical studies have confirmed the effectiveness of these different techniques. In one study by Bolivar, Cohen, and Fentress (1994), the subjects watched films of wolves engaged in various social interactions. These interactions had been prejudged as relatively friendly or aggressive in nature and were paired with mood-congruent or -incongruent music. Results indicated that relative to a no-music control group, ratings of the wolves' aggressiveness or friendliness significantly increased in the presence of "aggressive" or "friendly" music, respectively. Conversely, ratings of the same activities were diminished in the presence of mood-incongruent music. Similar effects have been demonstrated by others (e.g., Lipscomb \& Kendall, 1994; Marshall \& Cohen, 1988), and as a set these studies validate the role of music in conveying emotive meaning. 
Other studies have shown that in addition to influencing the overall emotional impact of a scene, music can bias the interpretation of visual events (e.g., Bullerjahn \& Güldenring, 1994; Lindner \& Hynan, 1987; Liu, 1976; McFarland, 1984; Parrott, 1982). For example, Boltz (2001) asked participants to view three ambiguous film clips accompanied by positive or negative music or none at all. Immediately after viewing each clip, one group was asked to extrapolate the film's ending and evaluate the motivations of the main characters. A second group was asked to return a week later for a surprise recognition memory test that assessed the remembering of certain objects within each film. The results revealed that relative to the no-music control group, positive and negative music biased viewers' interpretations and subsequent remembering of a film in a mood-congruent fashion. These findings indicate that music can provide an interpretive framework that clarifies the characters' temperaments and their relationships to one another, as well as clarifying their actions and underlying motivations. Music also guides attending toward those aspects of a film that are consistent with this framework, and thereby determines which elements are remembered best and which might be confabulated. In short, music contributes to a schematic structure that integrates a scene's action into one cohesive framework that directs the path of perception and attention, influencing both comprehension and memory.

\section{Music in Memory?}

Although it seems clear that music can become an integral aspect of film, it is not yet clear what happens to music after a scene has been viewed. Perhaps once music conveys its emotive message, it is discarded for further processing, much as the syntax of sentences is lost after the extraction of semantic meaning (Fillenbaum, 1966; Sachs, 1967; Wanner, 1974). Anecdotal evidence suggests that this is not the case, because we often find ourselves humming a theme song or recognizing soundtracks from movies we have seen. On an empirical level, some research provides insight into this issue, although this research is also limited in its scope and conclusions. Boltz, Schulkind, and Kantra (1991) examined the effect of certain film techniques upon remembering. Tunes that had been prejudged as positive or negative in their overall affect were paired with different film clips that resolved in a positive or negative ending. The mood congruency of these pairs was varied, as was the music's placement. A control group heard no music, but in two other conditions, music either foreshadowed or accompanied the films' resolution. Afterward, three surprise memory tasks were administered: free recall of all film clips; tune recognition; and cued scene recognition, in which subjects had to decide which of six scenes had been originally paired with a particular tune. The results of the film recall task revealed that in the accompanying condition, films with mood-congruent music were better remembered, but in the foreshadowing condition, expectancy violations arising from mood incongruencies were more memorable. The results of the two tasks assessing memory for music, however, were more inconclusive. Although tune recognition exceeded chance in some conditions, the primary finding was that positive tunes were more discriminable than negative ones. This finding suggests that the former were inherently more memorable than the latter-a possibility that was not assessed through a preliminary pretest. The results of the cued recognition task were equally inconclusive. Although people could remember which scene had originally co-occurred with a given melody, there was also a high level of false recognition. The nature of the design did not permit a signal detection analysis, so the level of discriminability independent of response bias effects could not be ascertained. In sum, the findings of this earlier experiment suggested that music might be encoded into memory, but the validity and reliability of these effects remain in question.

Suppose, however, that musical soundtracks are in fact encoded into memory during movie viewing. How does this process occur? One possibility is that music and film are jointly encoded as a unified entity. If so, then attending to one dimension should result in the incidental learning of the other, and no performance decrement should occur if attending is divided between both dimensions at once. In fact, instead of interference, a facilitation effect may occur in cases of dual attending: Given that music can provide an interpretive framework that allows one to generate inferences (Boltz, 2001), this situation may lead to an integration and elaboration of film information that enhances its memorability. The reverse situation may also apply, in such a way that the remembering of a music soundtrack is enhanced by the visual medium. Of these two scenarios, the former may be more likely than the latter, due to the visual dominance effect that often emerges when multiple modalities are available (Posner, Nissen, \& Klein, 1976).

A second possibility is that instead of a joint encoding, music and film are encoded independently of each other. A given dimension would then be well remembered if it was selectively attended to during a movie's viewing, but there would be no reason to expect an incidental learning of the second dimension as well. Performance on a divided attending condition would provide additional insight into the underlying attentional mechanisms at play. Some theorists, such as Kahneman (1973), have argued that a centralized mechanism is used by all tasks, regardless of their characteristics. Within the context of a film, attending to both music and film may exceed our cognitive capabilities - meaning that the memory of music and film information within a divided-attending condition should be much worse than that within unimodal conditions. Other researchers, however, have suggested that separate task-specific resources exist that do not interfere with one another (e.g., Navon \& Gopher, 1979; Wickens, 1984). Given that music and film rely on two different sensory modalities, separate processing 
capacities may be invoked that are specific to each medium. If so, there is no reason to expect an incidental learning of one dimension when attending to the other, and no interference effects should occur with divided attending.

A third possibility is that the encoding process depends on the structure of the film and, in particular, the degree of mood congruency between film and music. A joint encoding may be more likely to occur in cases of mood congruency in which musical affect can direct viewers' attending toward those aspects of a film with a similar connotative meaning and thereby integrate music and film into one coherent framework. Mood-incongruent music, on the other hand, may lead to independent encodings of film and music. Although mood incongruency is sometimes used for ironic contrast, the emotive meaning of music conflicts with that of the film, so that it is not always clear where attending should be directed or how the conflict of information can be resolved within one interpretative framework. Given that music and film seem relatively dissociated from each other in this situation, each may be encoded independently of the other.

Finally, in addition to the issue of encoding, there is also the question of how music and film are stored relative to each other in memory. If mood congruency leads to a joint encoding, this encoding may be reflected as a unified representation. On a behavioral level, this would mean that one medium should serve as an effective retrieval cue for the other, and viewers should be able to remember which particular scene was paired with a given soundtrack. Conversely, if incongruent relationships are encoded in an independent fashion, such encoding could also lead to independent memory representations. Behaviorally, one medium should not act as a retrieval cue for the other, and viewers should be unable to remember which scene was paired with a particular tune.

The existing literature sheds little light on these various issues. One exception in this respect is a study by A. J. Cohen (2004), who presented the participants with movie segments paired with the original soundtracks and instructed the participants that they would later be asked to recognize scene or music information. When performance on these tasks was compared with that of the participants who had either watched the film without music or heard the music alone, no differences were observed, indicating that the two modalities did not interfere with each other during encoding. A second study within this research revealed further evidence of an integrated memory code when it found that the participants could successfully remember the particular tune that had originally co-occurred with a particular scene. Such findings provide some initial insight into the cognitive processing of music/film information. However, some questions remain unanswered: First, it is unclear whether encoding occurs in a unified or an independent fashion. Although Cohen found that bimodal presentation results in the same level of recognition performance as unimodal pre- sentation, the lack of interference in the bimodal condition could result from either an allocation of task-specific resources or a joint encoding of music/film information. To distinguish between these two processes, one must manipulate and compare intentional with incidental learning of music/film information. Second, the potential impact of mood congruency has not yet been assessed. Although Pezdek and Stevens (1984) found that the degree of congruency between verbal dialogue and visual action can influence cognitive processing abilities, it is unclear whether these results generalize to mood relationships between music and film.

The purpose of the present research is to investigate these issues by means of two experiments. Experiment 1 is designed to examine (1) how selective attending influences the ability to remember each modality and (2) the nature of the subsequent memory representation. Experiment 2 acts as a converging operation to determine whether the results replicate and generalize to a cued recognition task.

\section{EXPERIMENT 1}

In Experiment 1, the participants viewed a set of film clips accompanied by a musical soundtrack whose mood was either congruent or incongruent with that of the video. The main manipulation involved the type of instructions administered to the participants: They were told to attend to and remember the filmed activities, the musical soundtracks, or both in tandem. Immediately afterward, three types of memory tasks were presented: One assessed visual memory; in it, the participants were asked to recall each of the film clips they had viewed earlier. A second, in which the participants had to decide which tune of a pair had previously been heard, tested music recognition. For the final task, the participants were required to distinguish those music/film pairs that had originally co-occurred (i.e., old-matched) from those that had previously been encountered within different pairings (i.e., old-mismatched).

This experimental design is similar to that of A. J. Cohen (2004) and Pezdek and Stevens (1984), but in lieu of varying what people were actually exposed to, the manipulation of selective attending allows one to administer the same set of memory tasks to all participants. By examining film recall and tune recognition for participants who attend to one modality alone, one can determine whether an incidental learning of the unattended dimension occurs and at a level comparable to that of intentional learning. The comparison of these conditions relative to the divided attending group is also important to reveal any interference effects that may emerge. Overall, then, these contrasts enable one to differentiae between a joint versus independent encoding strategy and whether this varies with mood congruency. The nature of the memory representation is addressed through the paired discrimination task and the ability to remember which tune accompanied a given scene. 


\section{Method}

\section{Design and Participants}

The experiment was a $2 \times 2 \times 3$ mixed factorial. All participants viewed a set of film clips in which each clip's final outcome was either positive or negative in overall affect. In one group, the mood of the accompanying soundtrack was congruent with that of a film's outcome, but in a second group, the relationship was mood incongruent. The second between-subjects variable was the particular dimension the participants were instructed to attend to (film alone, music alone, film and music).

Seventy-two participants from an introductory psychology course at Haverford College were tested in the experiment for course credit. Twelve were randomly assigned to one of the six betweensubjects conditions.

\section{Stimulus Materials}

Presentation phase. The filmed material was a set of film clips that had been used in a previous study by Boltz et al. (1991). They had been extracted from feature-length films and several television programs and consisted of 20 clips, each approximately 3-4 min in duration. Each clip represented an episode within the overall context of a story in that it was marked by a clear beginning and end; episode outcomes were not entirely predictable, but they were either distinctly positive or negative in their overall affect. Each film clip contained dialogue among its main characters but no background music in its original version.

A set of musical selections was also obtained from Boltz et al. (1991), consisting of 47 tunes that had been recorded from the same television programs as the film clips. All were approximately 20-30 sec in duration, of equal amplitude, and were performed by a single instrument with no accompanying lyrics. Half of the tunes displayed properties associated with positive affect - namely, a rapid tempo, major mode, and a wide variety of pitch changes; the remaining half displayed characteristics associated with negative affect - namely, a slow tempo, minor mode, and few changes in pitch (Hevner, 1936; Levi, 1982; Rigg, 1964; Scherer, 1979).

A set of pretests was then conducted to assess the relative affect, degree of familiarity, and overall memorability of these selections. In one, a group of 10 participants viewed a videotape of the 20 film clips and were asked to indicate for each, on a 7-point scale, whether a clip seemed familiar $(1=$ very familiar $)$ and how easy it would be to remember later $(1=$ very easy to remember $)$. In addition, the participants were asked to rate the affect of a film's outcome on a set of 13 bipolar adjectives using a series of 11-point Likert scales. These adjective pairs (shown in Appendix A) were based on Russell's (1980) multidimensional scaling model and represented the dimensions of activity/inactivity and pleasantness/ unpleasantness. An analogous procedure was used for the set of musical selections, in which a separate group of 10 participants evaluated each of the 47 tunes on the same dimensions.

The results of these two pretests were then used to develop the set of experimental stimuli. ${ }^{1}$ Of the 20 film clips, 8 were discarded due to their familiarity and/or extreme ratings of high or low memorability. The 12 remaining clips, shown in Appendix B, represented a subset of those used in the original Boltz et al. (1991) study and displayed a mean memorability rating of 5.33. A similar elimination process was used on the set of musical selections to yield a total of 24 tunes, 12 for the presentation phase of the experiment and 12 distractors for the tune recognition task. Overall, the tunes displayed a mean memorability rating of 5.17. The profiles for all film and music selections based on the 13 affect ratings were then compared, and those 12 tunes and film clips with similar levels of activity and (un)pleasantness were paired and labeled as mood congruent. In this set of stimuli, the activity level and mood of the tune accompanying the last $30 \mathrm{sec}$ of a scene were always consistent with the film's outcome. For the incongruent pairs, the same 12 tunes were paired with clips that displayed highly dissimilar patterns of ratings. An independent group of six judges confirmed the validity of all mood (in)congruent pairings. There were no instances in which a particular tune was paired with its original film clip.

Each set of film clips (congruent and incongruent) was arranged into two randomized orders. On each trial, a 1-sec warning tone preceded the presentation of a given film clip, which was then followed by a 90 -sec response period.

Materials for the tune recognition task. This phase of the experiment consisted of a two-alternative, forced choice decision task consisting of 12 trials. On each trial, a 1-sec warning tone preceded the presentation of two tunes separated by a 2-sec period of silence; a 5 -sec response period followed the presentations. One tune was a "new" distractor tune, the other was an "old" tune from the initial presentation phase. Both were matched for their overall affect, and total duration and amplitude were kept relatively constant across all trials. Two randomized orders were constructed for each (in)congruent stimulus condition.

Materials for the paired discrimination task. For this task, the last $30 \mathrm{sec}$ from each of the 12 film clips was recorded onto videotape. On half of the trials, this scene was paired with its original music from the presentation phase (i.e., old-match). On the remaining trials, the scene was paired with an old tune that had originally been paired with a different scene of a similar affect (i.e., old-mismatch). Two randomized orders were created for each congruency condition, and within each order, a trial consisted of a 1 -sec warning tone followed by a 1 -sec period of silence, the stimulus pair, and a 5 -sec response period.

\section{Apparatus}

A Panasonic AG-1950 video editing system, connected to two Panasonic VCRs and two NEC PM-1971 television monitors, was used to copy and edit the filmed material. Musical soundtracks were imposed by playing prerecorded music from a Kenwood KRV5570 stereo receiver through a Sima SSM-3 sound mixing board, which allowed any existing dialogue within a film to be preserved. The volume of the music was adjusted to approximately three quarters of the amplitude of the scene's dialogue.

During the actual experiment, participants viewed the set of film clips on a 19-in. Panasonic CT-20R12T television monitor interfaced with a Panasonic PV-2501 videocassette player.

\section{Procedure}

The participants were tested in small groups of 2-4 individuals and received recorded instructions relating the stimulus presentation details and task requirements. During the first phase, different groups of participants were instructed to attend to the film, the musical soundtracks, or both in tandem, because each group would later receive a memory test on their assigned dimensions. To enforce selective attending, the participants were also asked to rate each of their respective stimuli on the basis of the same adjective pairs used in the pretest.

Following this initial phase, all participants were administered three types of memory tests. The ordering of the first two tasks was counterbalanced across all participants, but the third was always presented last to minimize any carryover effects.

Film recall. For this task, all participants were given $20 \mathrm{~min}$ to provide a written recall for each of the film clips they had just viewed. They were told they could recall the clips in any order, but that they should provide as much detail as possible on the sequence of action, the main characters, and the final outcome.

Tune recognition. The participants in this task were presented with song pairs in one of two sets of randomized trials. During a 5sec response period after they heard each pair, the participants were asked to decide which melody of the pair ( 1 or 2 ) was "old" by circling the appropriate judgment on a response sheet.

Paired discrimination task. In this final task, the participants were assigned to one of the two randomized orders and shown the 
last $30 \mathrm{sec}$ of each film clip they had viewed earlier. Their task was to indicate on a response sheet whether the accompanying music was the same as or different from the original music they had heard with the clip.

\section{Results}

The primary data ${ }^{2}$ of interest are those from the three memory tasks, which were analyzed separately through a series of analyses of variance (ANOVAs). When significant differences emerged, mean differences were examined through Tukey HSD tests. Given that film instance and the various manipulations of counterbalance order exerted nonsignificant effects, mean performance was collapsed across these variables. The results of each task are shown in Table 1.

\section{Film Recall}

For each participant, response protocols were scored on an all-or-none basis for the percentage of clips that were correctly recalled. All protocols were evaluated by a set of three naive judges relative to the outlines depicted in Appendix B, and a unanimous decision was required for a correct response. No novel actions (i.e., confabulations) occurred, so all errors were those of omission.

The overall ANOVA revealed two significant effects. First, a main effect for congruency $[F(1,66)=9.78, p<$ $.01]$ indicated that films accompanied by music with similar affect were better remembered $(M=86 \%)$ than those with incongruent music $(M=69 \%)$.

Second, selective attending exerted a differential effect on music/film pairs of varying congruence $[F(2,66)=$ $12.02, p<.001]$. In the congruent conditions, those participants who focused on the films alone recalled, on average, $83 \%$ of the total clips. More important, those who directed their attending toward the musical excerpts also recalled $83 \%$ of the film clips - a result indicating an incidental learning of film information. Relative to either of these unimodal groups, recall was significantly enhanced $(M=92 \%)$ when attending was directed toward both film and music $(p<.05)$.

Incongruent pairings, on the other hand, yielded a different pattern of results. Recall was highest when the participants focused on the film alone $(76 \%)$, but it de- clined significantly $(p<.05)$ when attending was either directed toward music alone $(M=65 \%)$ or divided between the film and the music $(M=65 \%)$.

\section{Tune Recognition}

The tune recognition data were scored by determining the percentage of trials in which the old tune within a pair was correctly selected. There was once again a congruency main effect $[F(1,66)=7.84, p<.001]$ in which tunes from mood-congruent film pairs were better recognized $(M=79 \%)$ than those from mood-incongruent pairs $(M=66 \%)$. In addition, there was a significant interaction between congruency and selective attending $[F(2,66)=4.75, p<.05]$. In the congruent conditions, performance was best, and comparably so when attending was directed toward music alone or divided between film and music. Performance significantly decreased $(p<.01)$ when attending was directed toward film but was nonetheless significantly above chance $(p<.01)$, indicating that some incidental learning had occurred.

Mood-incongruent pairs not only displayed a consistently lower level of performance but a differential pattern of results. Although tunes were relatively well remembered if one focused on them at the time of encoding, recognition accuracy dropped to $58 \%$ when attending was directed toward film alone $(p<.01)$. Those participants who divided their attending between both film and music also displayed an interference effect $(M=60 \%)$ relative to those who focused on music alone $(p<.01)$.

\section{Paired Discrimination}

In order to assess the discrimination of matched from mismatched pairs, independent of response bias effects, a $d^{\prime}$ analysis was conducted from a procedure reported by Hochhaus (1972). For each condition of the experiment, hit rates were evaluated relative to false alarms and then transformed into $d^{\prime}$ and bias values by using the abscissa and ordinate values of the standardized normal distribution. Generally speaking, a $d^{\prime}$ value of 0 represents random guessing, whereas a value of 4.65 would represent perfect discrimination accuracy. Bias scores $(B)$ independently estimate whether participants are differentially inclined toward same or different responses.

Table 1

Mean Performance in the Memory Tasks of Experiment 1 as a Function of Mood Congruency and Selective Attending

\begin{tabular}{|c|c|c|c|c|c|c|c|c|}
\hline & \multicolumn{2}{|c|}{ Film Recall } & \multicolumn{2}{|c|}{ Tune Recognition } & \multicolumn{4}{|c|}{ Paired Discrimination } \\
\hline & $\%$ Correct & $S D$ & $\%$ Correct & $S D$ & $d^{\prime}$ & $S D$ & $B$ & $S D$ \\
\hline \multicolumn{9}{|c|}{ Congruent } \\
\hline Music alone & 83 & 4.75 & 85 & 3.50 & 2.75 & .28 & .87 & .03 \\
\hline Film alone & 83 & 3.01 & 65 & 6.18 & 1.68 & .37 & .87 & .05 \\
\hline Film + music & 92 & 2.67 & 87 & 3.83 & 3.33 & .22 & .95 & .01 \\
\hline \multicolumn{9}{|c|}{ Incongruent } \\
\hline Music alone & 65 & 8.03 & 79 & 6.87 & .40 & .63 & 1.21 & .32 \\
\hline Film alone & 76 & 7.15 & 58 & 8.31 & .31 & .57 & 1.06 & .18 \\
\hline Film + music & 65 & 6.67 & 60 & 8.09 & .36 & .70 & 1.18 & .27 \\
\hline
\end{tabular}


$B$ values of 1.00 reflect no bias, whereas values $>1.00$ indicate a bias toward "different" responses, and those $<1.00$ indicate a bias toward "same" responses.

The $d^{\prime}$ analysis revealed a main effect for congruency $[F(1,66)=17.58, p<.001]$ in which the participants were better able to remember which tune was paired with a given melody when there was a mood-congruent rather than an incongruent relationship. This effect, however, also depended on the direction of selective attending $[F(2,66)=15.75, p<.001]$. In the mood-congruent conditions, performance was above chance for all three attending groups but was best when the participants attended to both film and music in tandem. Memory declined when attending was directed toward music alone $(p<$ .05 ), and it did so even more when attending focused on film alone $(p<.01)$. In contrast, in the mood-incongruent conditions, the participants were unable to remember which tune was paired with a given film, regardless of what dimension was attended to. Discriminability did not vary from chance in all three attending groups.

The analysis of the bias scores simply produced a main effect of congruency $[F(1,66)=5.37, p<.05]$. Although values in the incongruent conditions were significantly greater than those in the congruent groups, none in fact varied from 1.00 - indicating that bias was effectively absent in all conditions of the experiment.

\section{Discussion}

The primary finding from this first experiment was that the encoding and remembering of music/film information is influenced by mood congruency. Across all three memory tasks, music/film pairs displaying incongruent relationships were less well remembered than were mood-congruent ones. This finding is consistent with previous research showing that mood-congruent music can direct attending toward relevant visual information (Bolivar et al., 1994; Boltz et al., 1991; A. J. Cohen, 2001; Marshall \& Cohen, 1988) and enable viewers to generate inferences about the characters' behavior (Boltz, 2001). The film's encoding, then, becomes a highly elaborated one that can easily be integrated into a coherent framework for subsequent retrieval. Incongruent pairs, on the other hand, display a musical affect that is seemingly unrelated to the sequence of activities. Given that there is no basis on which to integrate the film's activities into one interpretive framework, the remembering of both film and music is impaired.

The manipulation of selective attending further revealed that mood-congruent and -incongruent relationships led to different encoding strategies. In the pairings in which the mood of the music conflicts with that of the visual story, the encoding of each dimension appeared to occur independently of the other. Although film or music was relatively well remembered if it was selectively attended to at the time of encoding, there is little evidence that an incidental learning of the other dimension also occurred. In addition, music and film interfered with each other when attended to jointly, suggesting the mediation of a more centralized mechanism whose processing capabilities were exceeded by divided attending. Finally, the paired discrimination task revealed that all three attending groups displayed a chance level of performance and an inability to remember which tune was paired with a given film. Hence, mood-incongruent pairings not only lead to an independent encoding, but to nonintegrated memory representations as well.

Mood-congruent relationships, on the other hand, reflect both a joint encoding and a unified memory representation of music and film information. When attending was initially directed toward film or music, an incidental learning of the second dimension occurred as well. In addition, no interference occurred when the participants divided attending between both dimensions at once. The latter participants were able to recognize musical soundtracks as well did those who focused on music alone; in the case of film recall, the divided-attending group even remembered film clips better than did those who focused on the film alone. Lastly, across all three attending conditions, the participants were able to remember which tune originally accompanied a given film clip-indicating that the two dimensions became integrated into memory as a unified whole.

One final finding of note was a visual dominance effect that emerged consistently. Although it is difficult to compare performance between film recall and tune recognition tasks directly because of their differences, attending to music nonetheless was found to be more likely to result in an incidental learning of film than vice versa. Within the paired discrimination task, the participants were also better able to remember the particular pairings of film and music when they initially attended to the music rather than to the film. As a set, these findings indicate that film information is more likely to be encoded and subsequently represented within the cognitive system than is music.

\section{EXPERIMENT 2}

Experiment 2 was designed with two goals in mind. The first involved the issue of reliability: Would the results of the previous experiment generalize to a different set of participants within a different experimental paradigm? The second goal was to examine more closely the remembering of music/film pairs as a function of mood congruency.

The results of Experiment 1 indicated that moodcongruent pairings were not only jointly encoded into the cognitive system but were also represented as an integrated memory code. Given these findings, a corollary hypothesis would be that the presence of a given dimension should act as an effective retrieval cue for the other, and thereby facilitate remembering. In a tune recognition task, for example, the presence of the original scene in which the music occurred should enhance performance relative to conditions in which the scene is either 
absent or mismatched. In addition, this overall effect should emerge regardless of what dimension(s) participants initially attend to.

In contrast, visual scenes should not act as effective retrieval cues for mood-incongruent soundtracks. Recognition performance should be comparable regardless of whether a cue is present or absent, and in fact performance may improve in the absence of a cue, thus eliminating possible interference from a second dimension.

These ideas were tested in Experiment 2 by applying the manipulations of Experiment 1 within a recognition memory paradigm developed by Serafine, Davidson, Crowder, and Repp (1986). The participants were presented with the same set of music/film clips as before, in either mood-congruent or -incongruent relationships, and instructed to attend to and remember the filmed activities, the musical soundtracks, or both. Afterward, all participants performed only one memory task, tune recognition, in which they were required to discriminate old versus new tunes when cued with the original scene, with an old but mismatched scene, or in isolation. If the results converge with those of Experiment 1, tunes from mood-congruent pairs should be better recognized in the presence of their original scenes, but music from mood-incongruent pairs should be better recognized in isolation.

\section{Method}

\section{Design and Participants}

The experiment was a $2 \times 2 \times 3 \times 5$ mixed factorial. The participants viewed a set of film clips that each resolved to a positive or a negative ending. In one group, the accompanying music was mood congruent, in a second, it was mood incongruent. The participants were divided into three subgroups and instructed to attend to and remember the musical soundtracks, filmed events, or both. Afterward, a tune recognition test was administered that included five types of trials.

Seventy-two students from an introductory psychology class at Haverford College participated in the experiment for course credit. Twelve were randomly assigned to each of the six between-subjects conditions.

\section{Stimulus Materials}

The materials for the presentation phase were identical to those of Experiment 1. The same set of 12 old and 12 new melodies from the previous tune recognition task were used, but they were rearranged into randomized blocks of 18 trials. For the old tunes, 3 were paired with their original scenes (old-matched); 3 with an old scene that was not the original pairing but that had an affect similar to it (old-mismatched); and 3 with no scene at all. The 9 trials for new tunes consisted of 3 in which a tune was presented alone and 6 in which a new tune was paired with an old scene. In all cases, the visual scene was a static picture that represented the closing shot of a given film clip. Four sets of trial blocks were created in which each tune cued by its original scene in Set A was then cued by a mismatched scene in Set B, had no cue in Set C, and was absent altogether in Set D. Two different randomized orders for each set were developed.

All stimuli were digitized onto a set of four Power Mac 6115 computers and arranged into trial blocks via the PsyScope software program (J. Cohen, MacWhinney, Flatt, \& Provost, 1993). PsyScope was also used for the presentation of stimuli and the collection of keyboard responses.

\section{Procedure}

The participants were tested in small groups of 3-4 individuals. They were given the same set of instructions as in Experiment 1 and asked to perform the set of adjective ratings after each film clip. Following this phase, the tune recognition test was presented. On each trial, a 1-sec warning tone preceded the presentation of a melody by $2 \mathrm{sec}$, and if the tune was accompanied by a scene cue, the scene remained on the computer screen for the entire duration of the tune. The participants were instructed to decide whether the tune was "old" or "new" through keyboard responses on the computer console.

\section{Results}

A signal detection analysis was conducted to obtain measures of discriminability and response bias for each of the three tune types - namely, those cued by matched or mismatched scenes and those with no cue at all. For each participant, three of the new tunes paired with old scenes were randomly assigned to the matched condition and the remaining three to the mismatched condition. The percentage hit rate in each cue condition was then

Table 2

Mean Discrimination $\left(d^{\prime}\right)$ and Response Bias $(B)$ in the Tune Recognition Task of Experiment 2 as Functions of Mood Congruency, Selective Attending, and Type of Recognition Cue

\begin{tabular}{|c|c|c|c|c|c|c|c|c|c|c|c|c|}
\hline & \multicolumn{4}{|c|}{ Matched Cue } & \multicolumn{4}{|c|}{ Mismatched Cue } & \multicolumn{4}{|c|}{ No Cue } \\
\hline & $d^{\prime}$ & $S D$ & $B$ & $S D$ & $d^{\prime}$ & $S D$ & $B$ & $S D$ & $d^{\prime}$ & $S D$ & $B$ & $S D$ \\
\hline \multicolumn{13}{|c|}{ Congruent } \\
\hline Music alone & 3.74 & .09 & .96 & .03 & 2.70 & .21 & .92 & .05 & 2.64 & .32 & 1.05 & .08 \\
\hline Film alone & 2.67 & .18 & .87 & .06 & 2.07 & .33 & .89 & .11 & 1.83 & .45 & 1.01 & .10 \\
\hline Film + music & 3.95 & .06 & .98 & .01 & 2.83 & .19 & 1.03 & .02 & 2.67 & .28 & 1.06 & .05 \\
\hline Mean & 3.45 & & .94 & & 2.53 & & .95 & & 2.38 & & 1.14 & \\
\hline \multicolumn{13}{|c|}{ Incongruent } \\
\hline Music alone & .42 & .79 & .19 & .44 & .33 & .81 & .23 & .53 & 1.47 & .52 & .97 & .23 \\
\hline Film alone & .27 & .83 & .13 & .37 & .11 & .54 & .22 & .48 & .15 & .73 & .83 & .42 \\
\hline Film + music & .31 & .50 & .21 & .27 & .18 & .67 & .15 & .50 & .22 & .61 & .83 & .52 \\
\hline Mean & .43 & & .18 & & .31 & & .20 & & .68 & & .88 & \\
\hline
\end{tabular}


evaluated relative to the percentage of false alarms and transformed into $d^{\prime}$ and $B$ values using the procedure developed by Hochhaus (1972). The results are shown in Table 2.

An overall ANOVA on the $d^{\prime}$ scores revealed three significant findings: First, there was a main effect for congruency $[F(1,66)=19.69, p<.001]$ in which old tunes were better discriminated from new tunes when they were initially paired with a scene with a similar $(M=$ 2.79) rather than a dissimilar affect $(M=.38)$. Second, the effectiveness of a given memory cue varied with mood congruency $[F(2,66)=8.13, p<.01]$. In the moodcongruent conditions, melodies cued by their original scenes produced a significantly higher level of discriminability than those cued by old but mismatched scenes $(p<.01)$ or those lacking a visual cue $(p<.01)$. In contrast, melodies within the incongruent conditions consistently yielded a chance level of performance, regardless of the presence or absence of a cue. Lastly, a significant three-way interaction $[F(2,66)=10.03, p<.01]$ indicated that these effects were qualified by the variable of selective attending. In the mood-congruent conditions, discriminability was significantly above chance in all cases, and matched cues consistently resulted in a higher level of discriminability than either mismatched cues $(p<.05)$ or no cues $(p<.05)$; the latter two cuing conditions did not differ from each other. Although these effects applied to all attending conditions, those participants who attended to film alone showed a significantly lower level of performance than did those attending to either music alone $(p<.01)$ or both music and film $(p<.01)$. Incongruent pairings, on the other hand, yielded a chance level of performance in all cue conditions across all attending groups. The one exception to this result was those participants who attended to music alone during the encoding phase and were tested for tune recognition in the absence of any cue. Here, individuals were able to discriminate successfully between old and new melodies $(p<.05)$.

An analysis of the $B$ values revealed a significant congruency $\times$ cue interaction $[F(2,66)=7.97, p<.01]$. In the mood-congruent conditions, $B$ did not vary from 1.00 , thus indicating no bias effects. However, in the mood-incongruent conditions, tunes accompanied by old scenes (matched or mismatched) were biased toward "old" responses $(p<.05)$.

\section{Discussion}

The present set of results converges with those of Experiment 1 by indicating that the memory representation of music/film pairs varies with mood congruency. Those melodies paired with a film clip of similar affect not only were better recognized than melodies from incongruent pairs, but they also benefited from the reinstatement of their original film clips. The enhanced performance in the matched-cue versus the mismatched- and no-cue conditions was observed for those participants who initially attended to both film and music as well as for those who attended to music or film alone. These findings support the idea that mood congruent music/film pairs are jointly encoded, so that attending to one dimension leads to an incidental learning of the other. An integrated memory code results from this joint encoding, thus allowing scenes to act as effective retrieval cues for tune recognition.

With incongruent pairings, on the other hand, evidence once again emerged that music and film information were independently represented in memory. Regardless of where attending was directed, performance was at chance, and more important, a reinstatement of the original scene did not aid tune recognition. These findings confirm that with mood-incongruent pairings, attending to film alone is unlikely to result in an incidental learning of music, and in cases of divided attending, tune recognition is impaired due to interference effects. Only those participants who initially attend to music alone are able to successfully discriminate old from new melodies, and only then when melodies are presented with no scene information.

\section{GENERAL DISCUSSION}

The topic of mood congruency has long been of interest to psychology (see Bower, 2001, for a review). In general, the past research has found that material consistent with one's affective state is more likely to capture selective attending (e.g., Eich, Kihlstrom, Bower, Forgas, \& Niedenthal, 2000), to facilitate learning (e.g., Forgas \& Bower, 1987) and stimulus recognition (e.g., Schiffenbauer, 1974), and to enhance memory (e.g., Teasdale \& Fogarty, 1979). These effects occur regardless of whether mood is induced within individuals, is endogenous to clinical populations, or appears within cross-modal sources of information. The present research both converges upon and extends this literature by showing that moodcongruent relationships not only increase the remembering of music/film information relative to mood-incongruent relationships but also lead to different cognitive processing activities. Mood congruency promotes an integration of audiovisual information at the time of encoding that is reflected in a unified memory code. Conversely, moodincongruent relations result in independent encodings and memory representations.

On a theoretical level, these findings can be interpreted within a framework specifically developed to address the cognitive processing of music/film information. This framework, the "Congruence Associationist (CA) Model" (A. J. Cohen, 2001), is based on assumptions reflected in more general theories of cross-modal perception (Welch, 1999; Welch \& Warren, 1980). The basic idea is that the three main sources of information within a filmnamely, speech, music, and visual activities - are processed at four levels. At the most sensory level (A), the three channels of information are processed by separate modalities for their physical features. At the next level 
(B), however, cross-modal analyses occur in which the information is preattentively assessed for its degree of structural congruence and the number of stimulus properties that are shared. Much of this analysis is based on Gestalt laws, and when congruence occurs, the visual modality is assumed to receive primary attention. Vision typically dominates audition (Bertelson, 1999; Posner et al., 1976), and such dominance is particularly likely to emerge in filmmaking, in which the primary goal is the depiction of a visual story. From level B, the audiovisual information is then sent to consciousness, short-term memory, in which people construct a visual narrative and attempt to make sense of the film as a whole. This process $(\mathrm{C})$ is facilitated by top-down processing from level D in which long-term memory (LTM) is accessed to generate inferences (e.g., how characters typically behave in particular contexts).

The present research supports this approach and elaborates upon the nature of the processing mechanisms at play. Level B is most relevant, for there a cross-modal analysis occurs for the degree of structural congruence between audio and visual information. Mood congruency is a factor that will promote a high level of integration because as the previous literature has illustrated, the structural correlates of different moods are remarkably invariant across domains such as music, walking gaits (Montepare, Goldstein, \& Clausen, 1987; Sloman, Berridge, Homatidis, Hunter, \& Duck, 1982), facial expressions (Ekman, 1978; Ekman \& Friesen, 1975), and speech (Cosmides, 1983; Williams \& Stevens, 1979). Hence, during a movie's viewing, the affect of music will direct selective attending toward corresponding visual behaviors (Bolivar et al., 1994; Boltz et al., 1991; Marshall \& Cohen, 1988). For example, happy melodies typically display wide pitch variations, "bouncy" rhythms, and a relatively fast tempo (Hevner, 1936; Levi, 1982; Rigg, 1964; Scherer, 1979). If such a melody accompanies a "happy" scene, then attention should be guided toward similar properties within the ongoing visual action. Some support for this idea comes from Spelke (1979), who found that infants not only spend more time gazing at films with appropriate rather than inappropriate soundtracks, they also tend to focus on those visual actions corresponding to the music's tempo. The mood of music, then, attentionally highlights common patterns of audiovisual action that promote a unified encoding.

This integration process is a highly efficient one. As found in Experiment 1, dual attending to film and music within mood-congruent pairings produces no decrement in performance, indicating a preattentive level of processing that utilizes the same attentional capacity that would be required to input one dimension alone. This is in turn useful, because even though an individual may not attend to a given dimension at the time of encoding, that information will nonetheless be learned and represented in memory. In accordance with the assumptions of the C-A model, this process is also biased toward the visual modality, in that film information is more likely to be incidentally learned than is music.

A joint encoding of music and film information confers other advantages to the cognitive system. Given the cross-validation of affective information from two different sources, an individual can be more confident of those inferences generated about characters' behaviors, and this increased confidence should aid construction of the visual narrative within level $\mathrm{C}$ of the C-A model. Although this prediction remains to be explored, the results of the film recall task of Experiment 1 indicate that an elaboration process does enhance memory: Relative to the participants who attended to film alone, those who attended to both film and music showed a facilitation effect. Lastly, the joint encoding of music and film both persists and is represented as such in LTM. Moreover, this joint encoding is not simply a representation of mood information but of the acoustical qualities of music as well as the sequence of visual actions. This complexity increases the probability of retrieval, in that one dimension can act as an effective cue for the other. Such cuing in fact was observed in Experiment 2, in which the presence of a scene cue increased the participants' ability to recognize the tune that originally accompanied the scene.

In contrast, mood incongruency promotes independent encodings and subsequent memory representations. Within the framework of the C-A model, this lack of unity can be attributed to a lack of common stimulus properties between music and film. In such pairings, the structural dimensions specifying the mood of the music conflict with those associated with the visual action, so that attending is misguided toward irrelevant information. Given the lack of shared dimensions in which to integrate the two mediums, each appears relatively dissociated from the other, and events in each are therefore processed independently. Behaviorally, the film technique of ironic contrast is often used to alter the perceived meaning of characters' actions. For example, the juxtaposition of Rossini's "The Thieving Magpie" with the vicious murder scenes in A Clockwork Orange serves to underscore the pathology of the characters' actions. However, even though ironic mood information may be processed to influence the interpretation of events, the lack of common stimulus properties prevents a unitary encoding. Hence, in order for encoding to occur, one must selectively attend to one modality independently of the other.

The interference effects that occurred in the divided attending conditions of Experiment 2 suggest the mediation of a centralized mechanism that has exceeded its limitations. Theorists such as Kahneman (1973) argue that such interference stems from an overutilization of resources from a centralized pool. Others maintain that attending is impaired due to structural interference between the two modalities (e.g., Hirst \& Kalmar, 1987). Some support for the latter idea comes from the cued recognition task of Experiment 2. Here, tune recognition 
exceeded chance only when the participants focused on music alone and were later tested in the absence of any scene cue. The presence of scene information, then, appears to have interfered with the processing of music and thereby to have disrupted performance.

A final issue to consider is the wider ramifications of the present research. In many ways, the perception of film and music is analogous to that of faces and voices, so it would be worthwhile to examine whether mood congruency exerts a similar impact on encoding and remembering the latter stimuli. If so, then the processing of music/film information may represent an overgeneralization effect stemming from those cognitive mechanisms utilized in social perception. Questions also remain about the generality of results from the mood-incongruent conditions of the present experiments. On an experiential level, the use of ironic contrast often seems to result in a vivid memory of the film information. For example, ironically contrasted scenes from A Clockwork Orange are very memorable, perhaps even more so than they would be if they had originally been accompanied by moodcongruent music. It is important to note that the present set of stimuli consisted of relatively short film clips that were average in their degree of judged memorability and were simply matched with music on the basis of their respective mood and activity profiles. It may be that a different pattern of results would arise from using featurelength films and/or scenes that are more extreme in their inherent affects. The latter stimuli would provide enhanced distinctiveness, and the former would afford elaborative context for given scenes - factors that are both known to benefit memory. With the increased context of a longer film, one gains a deeper understanding of the story's plot and its cast of characters, and in these conditions ironic meaning may be more fully appreciated. If so, then this may provide a basis for integration that would be reflected in the nature of encoding and memory representation. Future research is needed to examine the mediation of these additional variables and, more generally, the extent to which viewers are able to integrate the different layers of film information for the purposes of interpretation and comprehension as well as of attending and remembering.

\section{REFERENCES}

Bertelson, P. (1999). Ventriloquism: A case of crossmodal perceptual grouping. In G. Aschersleben, T. Bachmann, \& J. Müsseler (Eds.), Cognitive contributions to the perception of spatial and temporal events (pp. 347-362). Amsterdam: Elsevier.

Bolivar, V. J., Cohen, A. J., \& Fentress, J. C. (1994). Semantic and formal congruency in music and motion pictures: Effects on the interpretation of visual action. Psychomusicology, 13, 28-59.

BoLTZ, M. G. (2001). Musical soundtracks as a schematic influence on the cognitive processing of filmed events. Music Perception, 18, 427454.

Boltz, M. [G.], Schulkind, M., \& Kantra, S. (1991). Effects of background music on the remembering of filmed events. Memory \& Cognition, 19, 593-606.

BORDWELL, D., \& THOMpson, K. (1979). Film art: An introduction. Reading, MA: Addison-Wesley.

Bower, G. H. (2001). Mood and social memory. In J. P. Forgas (Ed.),
Handbook of affect and social cognition (pp. 95-120). Mahwah, NJ: Erlbaum.

BullerJahn, C., \& GüLdenRING, M. (1994). An empirical investigation of effects of film music using qualitative content analysis. Psychomusicology, 13, 99-118.

Cohen, A. J. (2001). Music as a source of emotion in film. In P. N. Juslin \& J. A. Sloboda (Eds.), Music and emotion: Theory and research (pp. 249-272). Oxford: Oxford University Press.

Cohen, A. J. (2004). Processing of music and film: Independence and integration. Manuscript submitted for publication.

Cohen, J., MacWhinney, B., Flatt, M., \& Provost, J. (1993). PsyScope: An interactive graphic system for designing and controlling experiments in the psychology laboratory using Macintosh computers. Behavior Research Methods, Instruments, \& Computers, 2 257-271.

COSMIDES, L. (1983). Invariances in the acoustic expression of emotion during speech. Journal of Experimental Psychology: Human Perception \& Performance, 9, 864-881.

Eich, E., Kinlstrom, J. F., Bower, G. H., Forgas, J. P., \& Niedenthal, P. M. (2000). Cognition and emotion. London: Oxford University Press.

Ekman, P. (1978). Facial expression. In A. W. Siegman \& S. Feldstein (Eds.), Nonverbal behavior and communication (pp. 97-118). Hillsdale, NJ: Erlbaum.

Ekman, P., \& Friesen, W. V. (1975). Unmasking the face: A guide to recognizing emotions from facial cues. Englewood Cliffs, NJ: PrenticeHall.

Fillenbaum, S. (1966). Memory for gist: Some relevant variables. Language \& Speech, 9, 217-227.

FoRGAS, J. P., \& BowER, G. H. (1987). Mood effects on person-perception judgments. Journal of Personality \& Social Psychology, 53, 53-60.

GiannetTi, L. D. (1982). Understanding movies (3rd ed.). Englewood Cliffs, NJ: Prentice-Hall.

HeVNer, K. (1936). Experimental studies of the elements of expression in music. American Journal of Psychology, 57, 243-259.

HiRst, W., \& KALMAR, D. (1987). Characterizing attentional resources. Journal of Experimental Psychology: General, 116, 68-81.

Hochraus, L. (1972). A table for the calculation of $d^{\prime}$ and B. Psychological Bulletin, 77, 375-376.

Johnson, W. (1969). Face the music. Film Quarterly, 22, 3-19.

Kahneman, D. (1973). Attention and effort. Englewood Cliffs, NJ: Prentice-Hall.

LEVI, D. (1982). The structural determinants of melodic expressive properties. Journal of Phenomenological Psychology, 13, 19-40.

LindNer, D., \& Hynan, M. T. (1987). Perceived structure of abstract paintings as a function of structure of music listened to on initial viewing. Bulletin of the Psychonomic Society, 25, 44-46.

Lipscomb, S. D., \& Kendall, R. A. (1994). Perceptual judgment of the relationship between music and visual components in film. Psychomusicology, 13, 60-98.

LiU, A. (1976). Cross-modality set effect on the perception of ambiguous pictures. Bulletin of the Psychonomic Society, 7, 331-333.

Marshall, S., \& CohEn, A. J. (1988). Effects of musical soundtracks on attitudes toward animated geometric figures. Music Perception, 6 , 95-112.

MCFARLAND, R. A. (1984). Effects of music upon emotional content of TAT scores. Journal of Psychology, 116, 227-234.

Montepare, J. M., Goldstein, S. B., \& Clausen, A. (1987). The identification of emotions from gait information. Journal of Nonverbal Behavior, 11, 33-42.

NAVON, D., \& GopHER, D. (1979). On the economy of the human processing system. Psychological Review, 86, 214-255.

PARrott, A. C. (1982). Effects of paintings and music, both alone and in combination, on emotional judgments. Perceptual \& Motor Skills, 54, 635-641.

PezdeK, K., \& Stevens, E. (1984). Children's memory for auditory and visual information on television. Developmental Psychology, 20, 212-218.

Posner, M. I., Nissen, M. J., \& KLeIn, R. M. (1976). Visual dominance: An information-processing account of its origins and significance. Psychological Review, 83, 157-171. 
RIGG, M. G. (1964). The mood effects of music: A comparison of data from four investigators. Journal of Psychology, 58, 427-438.

Russell, J. A. (1980). A circumplex model of affect. Journal of Personality \& Social Psychology, 39, 1161-1178.

SACHS, J. S. (1967). Recognition memory for syntactic and semantic aspects of connected discourse. Perception \& Psychophysics, 2, 437442.

SCHERER, K. R. (1979). Acoustical concomitants of emotional dimensions: Judging affect from synthesized tone sequences. In S. Weitz (Ed.), Nonverbal communication: Readings with commentaries ( $2 \mathrm{nd}$ ed., pp. 240-253). New York: Oxford University Press.

SCHIFFEnBAUER, A. I. (1974). Effect of observer's emotional state on judgments of emotional state of others. Journal of Personality \& Social Psychology, 30, 31-35.

Serafine, M. L., Davidson, J. E., Crowder, R. G., \& Repr, B. H. (1986). On the nature of melody-text integration in memory for songs. Journal of Memory \& Language, 25, 123-135.

Sloman, L., Berridge, M., Homatidis, S., Hunter, D., \& Duck, T. (1982). Gait patterns of depressed patients and normal subjects. American Journal of Psychiatry, 139, 94-97.

SPELKE, E. S. (1979). Exploring audible and visible events in infancy. In A. D. Pick (Ed.), Perception and its development: A tribute to E. J. Gibson (pp. 221-235). Hillsdale, NJ: Erlbaum.

Teasdale, J. D., \& Fogarty, S. J. (1979). Differential effects of induced mood on retrieval of pleasant and unpleasant events from episodic memory. Journal of Abnormal Psychology, 88, 248-257.

WANNER, E. (1974). On remembering, forgetting, and understanding sentences: A study of the deep structure hypothesis. The Hague: Mouton.

WelCH, R. B. (1999). Meaning, attention, and the "unity assumption" in the intersensory bias of spatial and temporal perception. In G. Aschersleben, T. Bachmann, \& J. Müsseler (Eds.), Cognitive contributions to the perception of spatial and temporal events (pp. 371-387). Amsterdam: Elsevier.

Welch, R. B., \& Warren, D. H. (1980). Immediate perceptual response to intersensory discrepancy. Psychological Bulletin, $\mathbf{8 8}, 638-$ 667.

Wickens, D. D. (1984). Processing resources in attention. In R. Parasuraman \& D. R. Davies (Eds.), Varieties of attention (pp. 63-102). Orlando, FL: Academic Press.

Williams, C., \& Stevens, K. (1979). Emotions and speech: Some acoustical correlates. In S. Weitz (Ed.), Nonverbal communication: Readings with commentaries (2nd ed., pp. 233-248). New York: Oxford University Press.

\section{NOTES}

1. The use of all music and film material in this experiment conformed to the specifications of the House Report on Piracy and Counterfeiting amendments (House Report 97-495, pp. 8-9).

2. Although mood ratings were collected in Experiments 1 and 2, their primary purpose was to enforce selective attending toward a given dimension of music/film information. The results, however, converged with those from the pretest and thereby confirmed the construct validity of the experimental stimuli. The results were also consistent with previous research (Bolivar et al., 1994; Marshall \& Cohen, 1988; Lipscomb \& Kendall, 1994) showing that mood-congruent and -incongruent soundtracks serve to enhance or diminish, respectively, the emotional impact of filmed events.

APPENDIX A

Adjective Pairs Used in the Pretests and Presentation Phase of Experiments 1 and 2

\begin{tabular}{ll}
\hline Happy-Sad & Evil-Kind \\
Tense-Relaxed & Content-Frustrated \\
Disgusting-Appealing & Angry-Agreeable \\
Triumphant-Defeated & Surprised-Predictable \\
Serious-Lighthearted & Gentle-Boisterous \\
Aroused-Calm & Suspenseful-Unassuming \\
Malicious-Affectionate & \\
\hline
\end{tabular}

\section{APPENDIX B \\ Summary of the Film Clips Used as Experimental Stimuli}

\section{Positive Outcomes}

1. A woman enters her bedroom and begins to undress as she prepares to go to bed. She suddenly sees a man sitting in the corner of her room. As he points a gun at her, he tells her to continue to undress and take down her hair. He then stands, walks toward her, and they embrace. Her lover has returned. (From Butch Cassidy and the Sundance Kid, 1969, produced by Twentieth Century Fox, P.O. Box 900, Beverly Hills, CA 90213).

2. At home with her husband and daughter, a woman receives a phone call from her physician. The results of her AIDS test have just been received, and he schedules an appointment to see her. Later that afternoon, she meets with her physician and discovers that the test results are negative. (From Sweet As You Are, 1989, produced by BBC Productions, 630 Fifth Avenue, \#2220, New York, NY 10111).

3. A mob is trying to overrun a small-town jail in an attempt to capture one of the prisoners who is suspected of killing a young girl. The suspected prisoner escapes and forces another prisoner to change clothes (identities) with him. The mob is in the process of lynching the innocent prisoner when a police helicopter comes to his rescue. (From Alfred Hitchcock Presents, episode entitled "Incident in a Small Jail," 1985, Universal Television, Universal City, CA 91608). 


\section{APPENDIX B (Continued)}

4. A man is at home, quietly celebrating his own birthday, when two men knock on his door. They identify themselves as federal agents and say they have an arrest warrant for a murder he committed 20 years ago. Despite his protests of innocence and attempts by his lawyer to free him, the federal agents force him into their car and drive away. They soon arrive at a hotel where the agents' supervising officer is presumably waiting. After opening the door to the hotel room, the man is met by his wife and a surprise birthday party. (From $\mathrm{Al}$ fred Hitchcock Presents, episode entitled "Happy Birthday," 1986, Universal Television, Universal City, CA 91608).

5. A woman is delivering some groceries to her brother. As she crosses his lawn, several small explosives go off around her. The brother emerges from the bushes, laughing, and explains that the explosives were harmless. He was merely entertaining himself by scaring his sister. (From The Hitchhiker, episode entitled "Hootch," 1987, Lewis Chesler Productions, 7060 Hollywood Blvd., Suite 614, Hollywood, CA 90028).

6. A deaf boy hires a mob hit man to kill his father. After the father arrives home, the hit man emerges from the bedroom closet and approaches the boy from behind. He then places both hands around the boy's neck as if preparing to strangle him. Instead, he turns the boy around and they embrace. (From Alfred Hitchcock Presents, episode entitled “A Very Happy Ending," 1986, Universal Television, Universal City, CA 91608).

\section{Negative Outcomes}

1. A young woman enters a crowded restaurant and is seated at a table. She then places a bag under the table and immediately walks out the door. As she and a companion drive away in their car, the restaurant is "leveled" by a massive explosion. (From Exposed, 1983, produced by MGM-UA, 10000 W. Washington Blvd., Culver City, CA 90232).

2. Two policemen chase a woman, first in their car and later on foot. After catching her, they ask several questions about her brother who's hiding from the law. She refuses to answer and is severely beaten by the police. (From Shortstories, episode entitled "Face to Face," 1986, Ron Rapiel, 13929 Marquesas Way, \#312, Marina del Rey, CA 90292).

3. A man and a woman, divorced from one another several years ago, are on his houseboat near a marina. They reconcile and decide to live together on the boat. She borrows his car to get some of her belongings, but when she turns the ignition key, the car blows up and she is killed. (From Alfred Hitchcock Presents, episode entitled "Full Disclosure," 1988, Universal Television, Universal City, CA 91608).

4. A hotel attendant is working in the women's restroom and fantasizes about winning the state lottery. A wealthy customer then walks in complaining about the hotel staff and asks the attendant to remove a stain from her dress. As the attendant is doing so, the customer accidentally ruins the attendant's lottery ticket by spilling water on it. Later, after zipping up the customer's dress, the attendant strangles her and leaves her on the floor of the restroom. (From Shortstories, episode entitled "Greed: Pay to Play," 1986, ZDF Productions, 55100 Mainz, Germany).

5. A young man attempts to break into a classified government computer file containing data on genetically engineered people. He succeeds but finds his own name on the list. (From Shortstories, episode entitled "Happy Birthday Hacker John," 1986, Atlantis Films, Cinevillage, 65 Heward Ave., Toronto, ON, Canada M4M 2T5).

6. A young man is sitting on a rooftop at night, watching a young woman below as she follows his scribbled clues to a wall mural he has drawn for her. Uniformed officers suddenly arrive, and after hitting her several times, they take her away in an armored car. (From Shortstories, episode entitled "Graffiti," 1986, American Film Institute, 2021 North Western Ave., Los Angeles, CA 90027). 